\title{
Weibull Distribution and Geometrical Size Factor for Evaluating the Thermal Life of Electrical Machines' Insulation
}

\author{
Vincenzo Madonna $^{1}$, Paolo Giangrande ${ }^{1}$, Michael Galea ${ }^{1,2}$ \\ ${ }^{1}$ PEMC Group, University of Nottingham, Nottingham, NG72RD, UK, Vincenzo.Madonna1@ nottingham.ac.uk \\ ${ }^{2}$ Key Laboratory of More Electric Aircraft Technology of Zhejiang Province, University of Nottingham Ningbo China, \\ Ningbo 315100, China
}

\begin{abstract}
The thermal lifetime assessment of electrical machines' insulation systems is generally performed at the design and prototyping stages. Hence, the insulation system's thermal endurance curve (or temperature index) can be extrapolated, allowing the machine designer to tune lifetime prediction models and / or qualify a market-ready prototype, according to technical standards. The whole thermal evaluation process usually relies on accelerated thermal aging tests carried out on appropriate specimens, and an extensive economical effort could be needed. In this paper, a methodology relying on the Weibull statistical distribution and the geometrical size factor (i.e. statistical enlargement law) is analyzed for evaluating the machine's thermal life by using simple twisted pair as specimen. The obtained results are also experimentally validated against data collected on a different specimen's layout, namely random wound coils, confirming the feasibility of the analyzed approach.
\end{abstract}

Keywords-Accelerated Thermal Aging, Physics of Failure, Design of Experiments, Electrical Machines, Design of Insulation, Reliability

\section{INTRODUCTION}

In an electrical machine (EM), the insulation system accounts only for a fraction of the total weight and volume. However, its function is vital for the correct fulfilment of the whole electromechanical energy conversion process, as the insulation system plays the key role of providing galvanic separation among electrical conductors at different voltage potentials. This also means that any insulation failure within an EM can cause severe consequences, leading in most cases to complete out-of-service, if fault tolerant measures are not implemented [1-4].

Insulating materials employed in EMs are aged by various factors, generally grouped under the acronym "TEAM", namely, thermal, electrical, ambient, and mechanical stressors. Amongst them, the first two (i.e. thermal and electrical) represent the dominant failure modes, whilst the second two act mainly as "influence factors". Namely, they can further strengthen the negative impact of thermal and electrical aging on the insulation system's reliability. This is the case of e.g. partial discharges (PD) in EMs operating at high altitude $[5,6]$. In this case, the decrement of environmental pressure (i.e. "ambient" factor) with increasing altitude leads to a higher probability of PD inception (if the applied voltage is such that air ionisation can occur), as opposed to sea-level operations. Similarly, an insulation system which is already strongly deteriorated because of accumulated thermal aging, can easily fail if subject to mechanical shocks or vibrations, as in the case of EMs employed in the automotive sector [7].

These examples show how dominant stressors and "influence factors" simultaneously act on the EM insulation systems. Hence, the insulation lifetime assessment needs to be addressed via so-called multi-stress lifetime models, which are extremely complex from a mathematical point of view. Additionally, their calibration / fine-tuning requires extensive and time-consuming experimental campaigns. Therefore, under the assumption of prevailing aging factor, the simpler single-stress lifetime prediction models might be preferred. For instance, low-voltage (i.e. $<700 \mathrm{~V}_{\mathrm{rms}}$ ) EMs, either mainsfed or supplied by power electronics converters, must operate in absence of PD throughout their whole lifetime, due to the nature of the adopted insulating materials. In fact, insulation for low voltage EMs has generally an organic chemical composition, which is unable to withstand the onset of PD [8].

Accordingly, a machine designer aiming at assessing the insulation system's reliability of a newly-designed low voltage EM, can often employ a single-stress lifetime model, with temperature as the main aging factor. Despite this simplification, the insulation thermal life evaluation can be an extremely time-consuming process, as well as requiring extensive economical effort. Indeed, various specimens need to be manufactured and thermally-aged in strictly controlled conditions, until a sufficient number of failures are detected and a lifetime model can be calibrated. Clearly, the statistical significance of the lifetime model will also depend on the number of tested specimens and on the (non)censoring of the life data. Typically, the thermal lifetime evaluation procedure is only performed on the EM final design. However, this might unfortunately delay the time-to-market, if the design does not fulfil the reliability requirements dictated by industrial standards. Such risk can be mitigated by preliminarily knowing how the insulation system will behave in terms of reliability. To the purpose, accelerated thermal aging tests could be run on specimens, while the EM design is ongoing. The discussed intermedium reliability assessment provides useful information to be feed back into the EM design, minimizing the possibility of a negative outcome during the thermal lifetime evaluation on the machines's final design [9].

A preliminary thermal lifetime evaluation methodology for solid insulating materials employed in low voltage random wound EMs is discussed here. The proposed approach is based on the properties of the Weibull distribution and on the socalled geometrical size factor, or statistical enlargement law [10-15].

This theory assumes that, for a given insulating material, its lifetime (or failure probability) can have a direct link to the specimen's geometrical size. In this work, focus is given to the interturn insulation of a low voltage, random wound EM. For this reason, twisted pair specimens - made of round enamelled magnet wire - are initially employed for an accelerated thermal aging campaign. The obtained results are then postprocessed through the Weibull distribution and the size factor theory, and used for predicting the thermal lifetime of random wound coils. The appropriateness of the methodology is experimentally verified through comprehensive thermal aging tests carried out on random wound coil specimens. Whilst the analysis performed here is focused on random wound EMs, 
the obtained results can be potentially extended to other insulating sub-systems, materials and winding arrangements.

\section{Thermal AgING In SOlid Insulating MATERIALS}

The thermal aging is one of the principal causes of progressive deterioration and failure of the insulation system of rotating EMs [16-18]. The "reliability" is defined as the ability of a system to satisfactorily perform its intended duty for a specified time-span and for a given operating environment. Therefore, the reliability of a rotating EM strongly depends on the thermal aging level of its insulation system.

The main duty of an electrical insulating material is to ensure galvanic separation between electrical conductors, which are at different voltage potential. From the chemical / physical point of view, as the thermal aging level in an electrical insulating material accumulates, its voltage withstanding capability decreases, leading to failure when the operating voltage cannot be withstood anymore $[16,19]$. This because the thermal stress (i.e. temperature) triggers chemical reactions (mainly oxidation) in insulating materials. The onset of these reactions leads to cracks, delamination and in general structural weakening within the insulation [20], thus negatively impacting on its ability to provide dielectric separation. The thermal life of insulating materials is typically modelled through an Arrhenius-type law, where the life $L$ is related to the absolute temperature $\theta$ through a first order chemical reaction. The Arrhenius law is described by (1), where $A$ and $B$ are material dependent constants.

$$
L(\theta)=A \cdot e^{\frac{B}{\theta}}
$$

The popular "10 degrees rule", which states that the insulation life is halved every time the temperature increases by $10{ }^{\circ} \mathrm{C}$ is an approximation of (1) and it was discovered empirically in 1930 by Montsinger [21] which analysed the thermal life of power transformers. Later in 1947, Dakin proposed for the first time the treatment of thermal aging in electrical insulating materials through the Arrhenius law (1) [22]. Since then, all the major technical standards [23, 24] and literature [25-27] on thermal evaluation and qualification of insulating systems and materials are based on this important chemical law.

Without going too deep into the physics of dielectrics, the electrical breakdown in solid insulating materials is governed by a large number of phenomena, including: a) intrinsic breakdown, b) streamer breakdown, c) electromechanical breakdown d) treeing, e) thermal breakdown, f) erosion breakdown and g) tracking [28]. Independently on the breakdown mechanism, the voltage withstanding capability of a thermally aged dielectric system is lower than its unaged counterpart [16, 20, 28, 29]. This because thermally-activated chemical reactions induce physical and chemical modifications within the dielectric structure (e.g. depolymerisation in organic polymers employed in low voltage EMs). Thus, a thermally-aged solid insulating material can fail by cracking, melting, blistering decomposing and burning when subject to an electric field (i.e. applied voltage potential) [29]. As thermal aging accumulates, the material becomes weaker and weaker and thus its probability of failure increases.

Fig. 1 reports a microscopy enlargement comparing the diameter of an unaged and a thermally aged Grade 2, $0.4 \mathrm{~mm}$ magnet wire (i.e. typically used for the winding of low voltage EMs) [30]. The thermally aged wire shows a considerable thickness reduction caused by depolymerisation of the organic enamel insulation. This means that for a given applied voltage (between two adjacent turns), the thermally aged wire will have a higher probability of failure with respect to the unaged one, mainly for the three following reasons:

1. Electromechanical breakdown, caused by a compressive force between two adjacent wires exposed to a different voltage potential (i.e. attraction force between opposite polarity space charges);

2. Increased dielectric loss (i.e. dissipation factor, or $\tan \delta)$ as discussed in [31].

3. Onset of extrinsic electric aging caused by partial discharges inception.

The first two points are likely to represent the dominant failure causes if the partial discharge inception voltage is not exceeded (that is the condition at which low voltage EMs must operate, according to the technical standard IEC 60034-18-41 [32]).

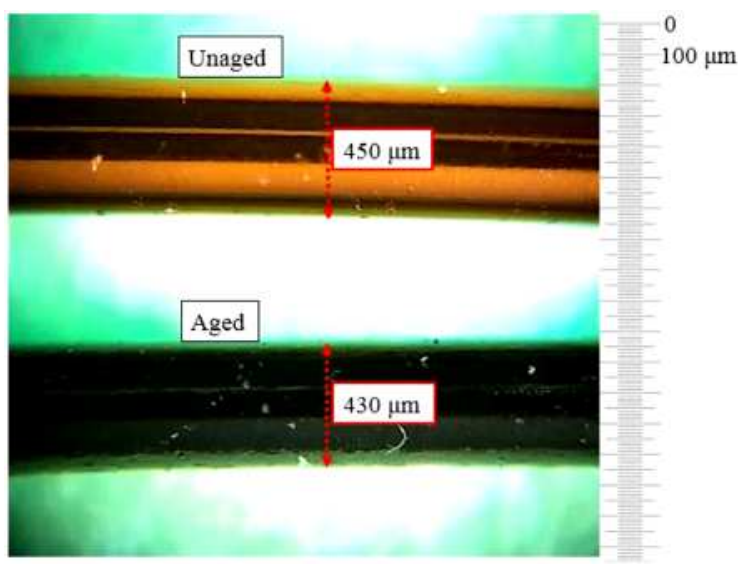

Fig. 1. Microscopy enlargement of an unaged and thermally aged, Grade 2, $0.4 \mathrm{~mm}$ magnet wire.

\section{WEIBULl DiSTRIBUTION AND SIZE FACTOR}

The two-parameter Weibull distribution is a commonly adopted statistical tool for post-processing the data deriving from accelerated lifetime tests. Its strength lies on the ability of modelling either increasing, decreasing or constant failure rates. The Weibull reliability function is described by (2), where $\alpha$ is the scale parameter (i.e. 63.2 ${ }^{\text {th }}$ percentile of failure time), $\beta$ is the shape parameter and $t$ is the time to failure.

$$
R(t)=\exp \left[-\left(\frac{t}{\alpha}\right)^{\beta}\right]
$$

By defining the cumulative distribution function as $(1-R(t))$, the so-called Weibull probability plot can be obtained. The latter reports the percent cumulative probability on the y-axis and the logarithm of failure times on the $\mathrm{x}$-axis. Therefore, data deriving from accelerated lifetime tests are said to be Weibull distributed if they can be fitted through a straight line on a Weibull plot. An example of Weibull probability plot is reported in Fig. 2, where the $50^{\text {th }}$ (i.e. median) and the $10^{\text {th }}$ (i.e. B10) percentiles of failure times are also outlined [25]. In this case, it can be graphically verified a good fit between the failure data points and the fitting curve.

The life data deriving from accelerated thermal aging tests are generally well fitted through the Weibull distribution [25]. Further, if identical sets of specimens are thermally aged at different temperatures, their cumulative distribution function, 
reported on a Weibull plot, are likely to have a similar slope (i.e. $\beta$ ). From a physics of failure perspective, this means that the samples are characterised by the same failure mode [10]. In reality, since it is possible that the $\beta$ parameter is not precisely identical among samples stressed at different temperatures, a common slope is selected (i.e. a value of $\beta$ which provide the best fits among the experimentally recorded data).

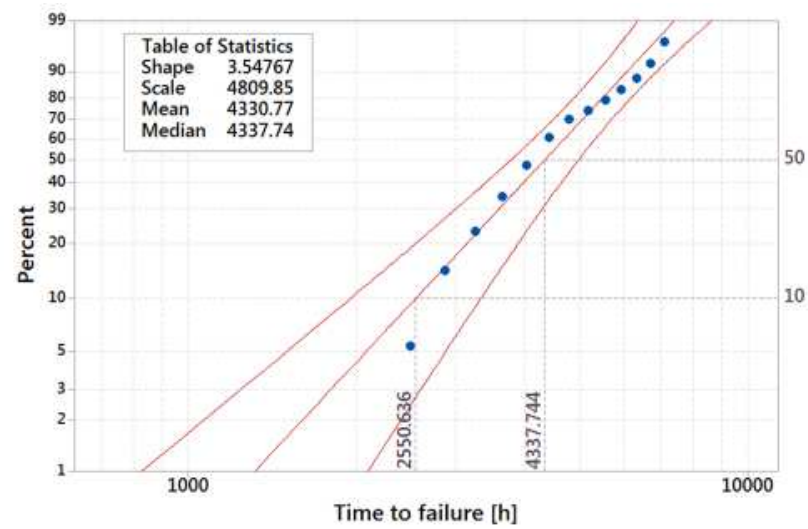

Fig. 2. Example of Weibull probability plot .

Under the assumption of a dominant failure mode (and thus a similar Weibull shape factor) among various samples, aged at different temperatures, an important property of the Weibull distribution is valid, i.e. the probability of failure can be considered proportional to the specimens' geometrical size, (here is the definition "size factor"). To note here that similar approaches are also applicable to lifetime data (i.e. failure times) following different statistical distributions, although these are not discussed in this paper.

In practical terms, given a generic specimen $S P 1$ whose dimension (i.e. volume, length, number of turns etc...) is $\rho_{S P I}$ and the Weibull distribution has shape parameter $\beta$ and scale parameter $\alpha S P 1$, then, a specimen $S P 2$, with dimension $\rho_{S P 2}$ will feature a Weibull distribution having the same shape parameter $\beta$, while the scale parameter is calculated as in (3)Error! Reference source not found. Error! Reference source not found. [10].

$$
\alpha_{S P 2}=\frac{\alpha_{S P 1}}{\left(\frac{\rho_{S P 2}}{\rho_{S P 1}}\right)^{1 / \beta}}
$$

Equation (3) is obtained by assuming a given specimen as a reliability-series system of identical, statistically-independent sub-systems with reduced geometrical size.

If this important property holds true for thermally aged insulating materials employed in EMs, then it can be exploited for simplifying the thermal lifetime evaluation of machine's insulation system. In fact, the lifetime results deriving from aging tests carried out on (geometrically) scaled-down insulation specimens, could be extended in principle to the whole machine. This would enable savings both from an economic perspective, as well as from a time point of view. Further, if the manufacturers of the EM's insulating materials provide comprehensive life data, these could be also exploited by implementing them in the size factor equation.

In Section V, an experimental validation of the size factor equation will be provided for round enamelled magnet wires, typically used in low voltage EMs windings.

\section{EXPERIMENTAL INVESTIGATION}

The main objective of this Section is to presents the results of accelerated thermal aging tests performed on reduced-size specimens of low voltage EMs' windings (i.e. twisted pairs), and then employ these to extract the thermal lifetime of a larger-size specimen layout (i.e. coil) through the size factor theory.

\section{A. Experimental Investigation on Twisted Pairs}

Three sets of 10 twisted-pair specimens each have been prepared according to the technical standard IEC 60172 [33] as reported in Fig. 3. The main properties of the adopted magnet wire are listed in Table I, where the average specimen's length is also reported.

TABLE I. MAGNET WIRE AND TWISTED PAIRS PROPERTIES

$\begin{array}{cc}\text { Parameter } & \text { Property } \\ \text { Copper diameter } & 0.400 \mathrm{~mm} \\ \text { Grade } & 2 \\ \text { Thermal class } & 200 \\ \text { Base coat insulation } & \text { Polyester-imide } \\ \text { Over coat insulation } & \text { Polyamide-imide } \\ \text { Average (twisted) length } & 120 \mathrm{~mm}\end{array}$

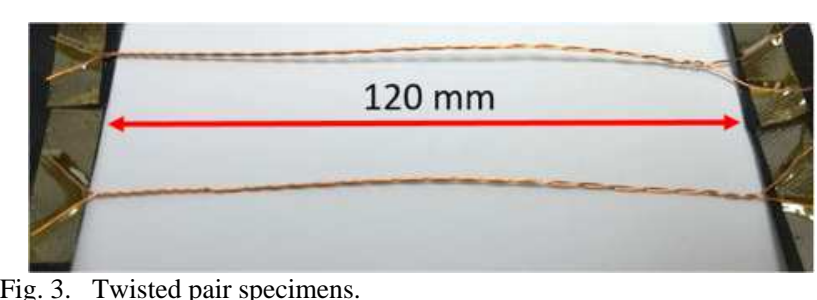

Each of the three sets has been aged at a different temperature, above the declared thermal class in an environmental chamber as shown in Fig. 4. Throughout the aging campaigns, the specimens insulation condition has been assessed through the AC electric withstand test [33], during the so-called diagnostic sessions, which are carried out at the end of each exposure cycle. Therefore, the end-of-life criterion is the dielectric breakdown, which is selected in accordance to the technical standard IEC 60172. The three aging temperatures and relative exposure cycle durations are reported in Table II.

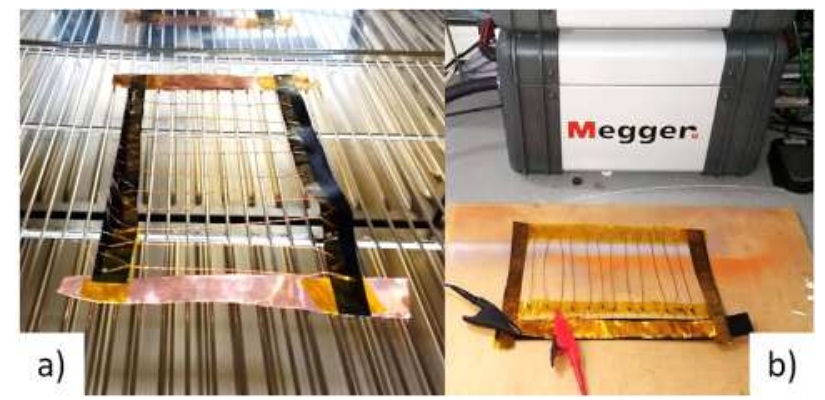

Fig. 4. Twisted pair specimens, a) thermal aging in environmental chamber, b) AC electric withstand test.

TABLE II. AgING TEMPERATURES AND EXPOSURE CyCle DuRATIONS

Temperature $\left[{ }^{\circ} \mathrm{C}\right] \quad$ Exposure cycle duration $[\mathrm{h}]$

$\begin{array}{cc}250 & 120 \\ 270 & 24 \\ 290 & 8\end{array}$

The results from the accelerated thermal aging tests are summarised in Table III, where the parameters of the Weibull distribution are listed. As expected, the Weibull scale factor (i.e. $63.2^{\text {th }}$ percentile of failure time) decreases as the aging temperature is increased, according to the Arrhenius law (i.e. (1)). On the other hand, the shape factor $\beta$ is only slightly influenced by the temperature variation, although its value 
tends to increase with temperature, indicating that perhaps secondary chemical reactions are triggered during thermal aging exposures at higher temperatures.

TABLE III. Results From ACCELERATED Thermal AgING TeSts on Twisted PAIRS

\begin{tabular}{cccc} 
& \multicolumn{3}{c}{ Temperature } \\
Parameter & $250{ }^{\circ} \mathrm{C}$ & $270{ }^{\circ} \mathrm{C}$ & $290{ }^{\circ} \mathrm{C}$ \\
$\alpha[h]$ & 1943 & 415 & 111 \\
$\beta$ & 2.73 & 3.67 & 5.93 \\
Median [h] & 1699 & 375 & 104
\end{tabular}

\section{B. Size Factor Sensitivity Analysis}

At this point, it is possible to verify whether or not the Weibull size factor property holds true for the examined round enamelled magnet wire. For doing so, another specimen's topology needs to be selected, with different geometrical dimensions with respect to the tested twisted pairs. In this case, in order to assess the interturn insulation condition random wound coil specimens are prepared. Each coil is formed by two sub-coils with 20 turns each as depicted in Fig. 5.a, held together by Kapton ${ }^{\circledR}$ tape as shown in Fig. 5.b. The average length of a single turn is $\approx 300 \mathrm{~mm}$. Being the coils randomly wound (as it is typically done in low voltage EMs), it is not possible to apply directly (3) for calculating their Weibull scale factor $\alpha$. This because amongst different coil specimens, the number of touching turns (being at a different voltage potential) might significantly vary. In other words, it is highly unlikely that all the 20 turns of sub-coil 1 are in direct contact with all the 20 turns of sub-coil 2.
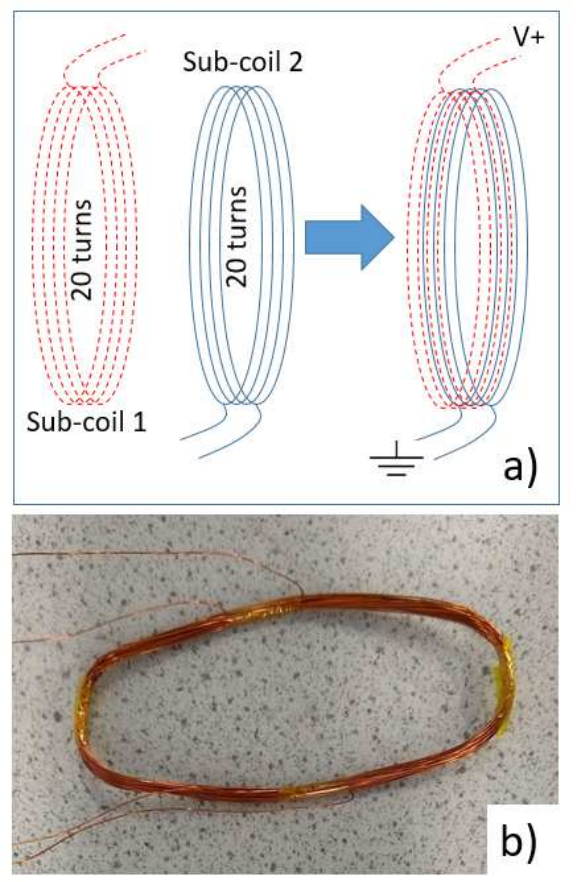

Fig. 5. Random wound coil; a) layout, b) manufactured specimen.

However, a sensitivity analysis can be performed, by varying the number of touching turns from 1 to 20 and calculating through (3) the possible variation range of the coils' $\alpha$, for the three different aging temperatures. Accordingly, $\rho_{S P I}$ is the twisted pair's average length (i.e. 120 $\mathrm{mm}$ ), whilst $\rho_{S P 2}$ is a linear function of the number of touching turns $k$, defined as in (4), where $l_{c}$ is the average turn length (i.e. $300 \mathrm{~mm}$ ).

$$
\rho_{S P 2}=k \cdot l_{c} \quad k=1,2, . .20
$$

Thus, by replacing (4) in (3), three sensitivity analyses can be carried out (i.e. one for each temperature) by simply varying $k$ and computing the resulting Weibull scale factor for the random wound coils. The results of the sensitivity analysis are graphically presented in Fig. 6. A larger scale factor variability range is observed for the results relative to $250{ }^{\circ} \mathrm{C}$ aging temperature as opposed to the other two temperatures. This is directly linked to the experimentally-derived $\beta$ for the twisted pairs. Indeed, by observing the data in Table III, it can be noted that $\beta$ for the twisted pairs aged at $250{ }^{\circ} \mathrm{C}$ is considerably lower with respect to $\beta$ relative to 270 and 290 ${ }^{\circ} \mathrm{C}$ temperatures. This indicates a larger variance amongst the experimentally recorded failure times (in fact, the Weibull shape factor is inversely proportional to the data scatter).
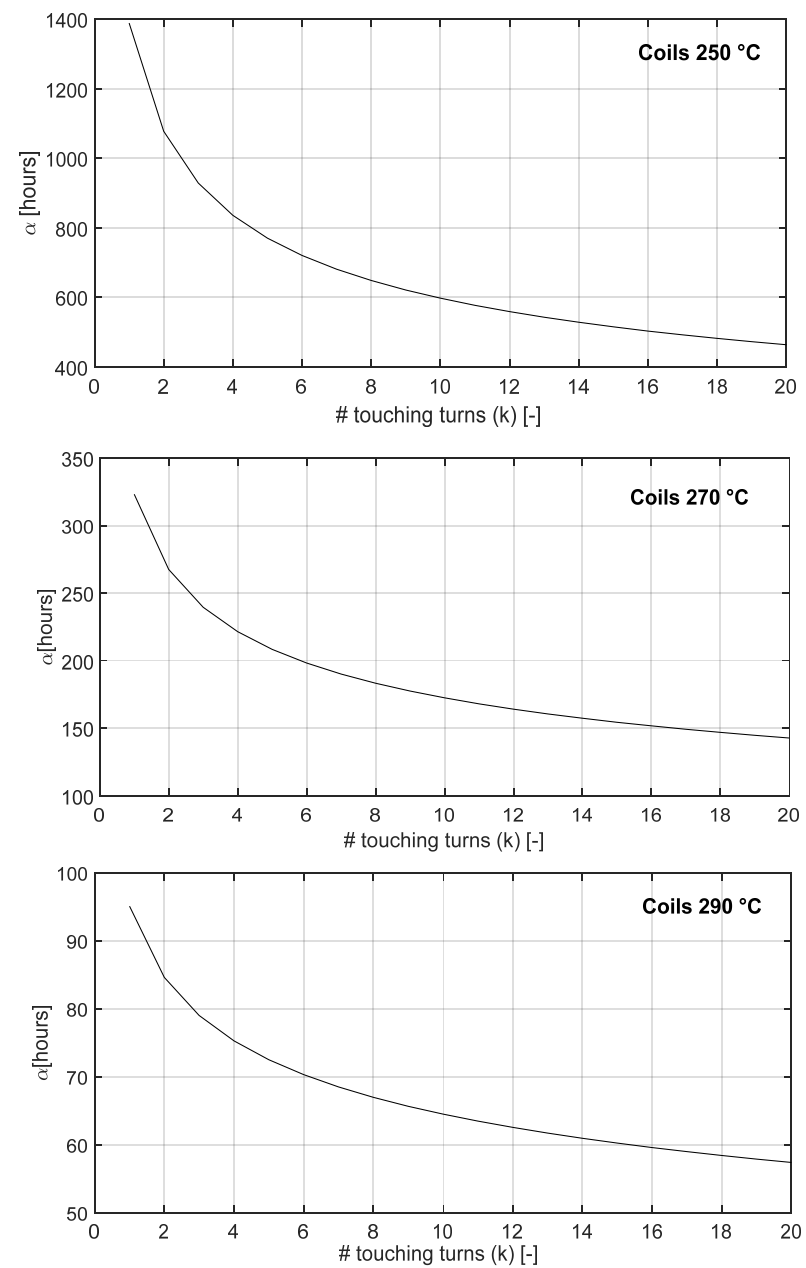

Fig. 6. Calculated Weibull scale parameter sensitivity analysis for the coils aged at $250{ }^{\circ} \mathrm{C}$ (top sub-plot), $270{ }^{\circ} \mathrm{C}$ (middle sub-plot) and $290{ }^{\circ} \mathrm{C}$ (bottom sub-plot).

\section{VALIDATION AND DiscUSSION}

In this Section, the methodologies described in Section IV, and in particular the data summarized in Fig. 6, will be experimentally validated. For this purpose, three sets of 10 random wound coils each, identical to the one shown in Fig. 5 , have been manufactured. These have been thermally aged following the exact same procedure carried out for the twisted pair specimens (see Section IV). The failure times have been recorded throughout various diagnostic sessions and postprocessed through the two-parameter Weibull distribution.

The experimentally-recorded failure times are reported in a Weibull probability plot as shown in Fig. 7, whilst the 
Weibull scale factors are tabulated in Table IV. At this point it is possible to verify the accuracy of (3) in predicting the thermal life of round enameled magnet wire windings. For doing so, the experimentally measured $\alpha$ parameters of the coil specimens, need to be apprised to those predicted through (3) and summarized in Fig. 6.

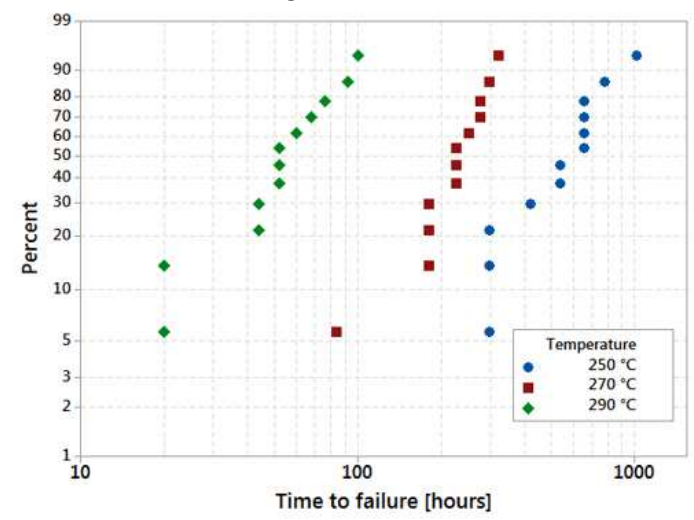

Fig. 7. Failure times for the coil specimens aged at three different temperatures.

TABLE IV. Results From ACCELERATED THERMAL Aging TeSTS ON CoILS

\begin{tabular}{cccc} 
Parameter & \multicolumn{3}{c}{ Temperature } \\
& $250{ }^{\circ} \mathrm{C}$ & $270{ }^{\circ} \mathrm{C}$ & $290{ }^{\circ} \mathrm{C}$ \\
Predicted $\alpha$ range $[\mathrm{h}]$ & $463-1390$ & $143-323$ & $57-95$ \\
Measured $\alpha[\mathrm{h}]$ & 640 & 251 & 64
\end{tabular}

In all three cases (i.e. for all the three tested temperatures), the $\alpha$ derived from accelerated thermal aging tests performed on the coils lies within the range provided by the sensitivity analyses of Fig. 6. Because of the random nature of the coils, the range of $\alpha$ variation in Fig. 6 is quite wide, particularly for $250{ }^{\circ} \mathrm{C}$ aging temperature. The obtained results might indicate that if the same analysis is performed for formwound coils, where the precise winding layout is known, a more accurate thermal life prediction can be attained. However, even for low voltage, random wound EMs insulation important information can be extracted from the predicted range of $\alpha$ variation (see Fig. 6 and Table IV). In particular, the thermal endurance curve can be plotted [34] as shown in Fig. 8, where the predicted Arrhenius plots (i.e. upper and lower confidence bands) are reported. In addition, Fig. 8 includes also the "measured" Arrhenius plot, namely, the thermal endurance curve derived from the accelerated thermal aging tests on the coil specimens (i.e. relative to the failure times in Fig. 7).

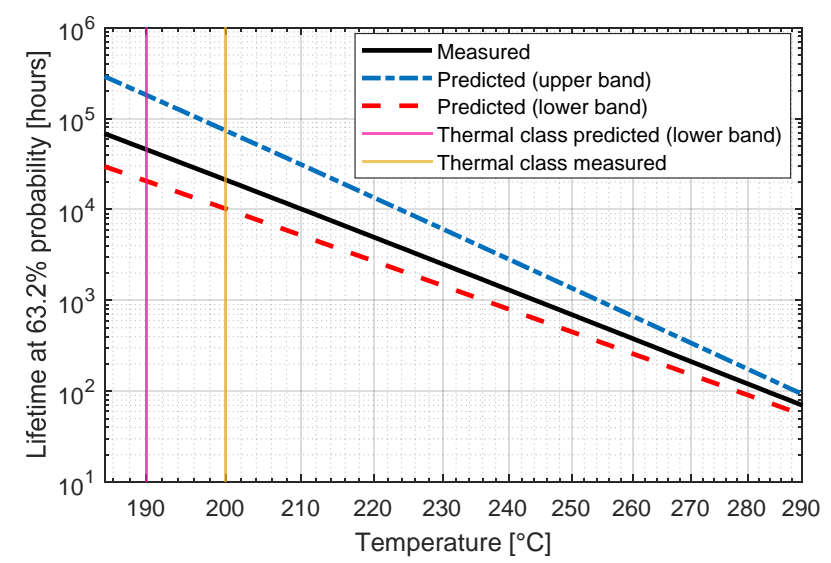

Fig. 8. Coils' Arrhenius plot corresponding to the $63.2^{\text {th }}$ percentile of failure times (i.e. $\alpha$ of the Weibull distribution).
Although the predicted life interval-range is quite wide, due to the random nature of the coil specimens, its lowervalue band (i.e. computed by replacing $k=20$ in (4)) can actually provide a conservative estimation of the coils' thermal class. Indeed, the predicted thermal class (i.e. temperature corresponding to 20,000 hours life) is $190{ }^{\circ} \mathrm{C}$, whilst the measured one is $200^{\circ} \mathrm{C}$. Despite the $10{ }^{\circ} \mathrm{C}$ absolute error, it must be pointed out that according to the presented approach, the thermal class of a complete EM can be straightforwardly estimated by performing accelerated thermal aging tests on a much simpler specimen layout, namely the twisted pair.

In addition to the point above, magnet wire manufacturers often provide the wire's Arrhenius plot, derived from thermal aging tests on twisted pairs [24, 33]. This means that a preliminary thermal class estimation for a complete EM's interturn insulation system can be performed without carrying out any tests at all, by applying the size factor formula. Here it should be however noted that the end of life criterion adopted by magnet wire manufacturers might not be representative of the typical failure mode(s) encountered during EMs' actual service operations, and thus thermal aging tests on twisted pairs are advisable.

\section{CONCLUSION}

Evaluating the thermal lifetime of a newly designed electrical machine can be an extremely time-consuming as well as economically incumbent procedure. Nonetheless, in several cases, the machine designer needs to have an idea regarding the thermal life of a machine's insulation system during the initial prototyping. At this stage, it is unlikely that thermal aging tests can be performed on the complete machine, since it has not been completely designed yet. However, tests on physically representative specimens are usually the norm.

In this work, the validity of an important concept, namely the size factor, usually employed in accelerated lifetime testing is experimentally proved for the inteturn insulation of electrical machines. Its application allows through accelerated thermal aging tests performed on simple twisted pair specimens, to predict the thermal life of a much more complex winding arrangement (i.e. the coil). What presented in this paper can be thus a tool allowing machine designers and manufacturers to save considerable amount of time and money throughout the initial prototyping stage of a new product.

\section{REFERENCES}

[1] P. Giangrande, V. Madonna, S. Nuzzo, and M. Galea, "Design of FaultTolerant Dual Three-Phase Winding PMSM for Helicopter Landing Gear EMA," in 2018 IEEE ESARS-ITEC, 2018, pp. 1-6.

[2] V. Madonna, P. Giangrande, C. Gerada, and M. Galea, "Thermal analysis of fault-tolerant electrical machines for aerospace actuators," IET Electric Power Applications, vol. 13, no. 7, pp. 843-852, 2019.

[3] G. Sala, M. Mengoni, G. Rizzoli, L. Zarri, and A. Tani, "Decoupled dq Axes Current Sharing Control of Multi Three-Phase Induction Machines," IEEE Transactions on Industrial Electronics, pp. 1-1, 2019.

[4] G. Sala, G. Valente, D. Gerada, P. Zanchetta, and C. Gerada, "PostFault Operation of Bearingless Multisector SPM Machines by Space Vector Control," IEEE Transactions on Power Electronics, vol. 35, no. 4, pp. 4168-4177, 2020.

[5] D. Roger, S. Ait-Amar, E. Napieralska-Juszczak, and P. Napieralski, "Proposition for Improving the Design of Motor Windings for LowPressure Environment," IEEE Transactions on Industry Applications, vol. 56, no. 3, pp. 2491-2499, 2020. 
[6] C. Abadie, T. Billard, and T. Lebey, "Partial Discharges in Motor Fed by Inverter: From Detection to Winding Configuration," IEEE Transactions on Industry Applications, vol. 55, no. 2, pp. 1332-1341, 2019.

[7] H. Zhang et al., "Thermal Model Approach to Multisector Three-Phase Electrical Machines," IEEE Transactions on Industrial Electronics, pp. $1-1,2020$.

[8] M. Ghassemi, "Accelerated insulation aging due to fast, repetitive voltages: A review identifying challenges and future research needs," IEEE Transactions on Dielectrics and Electrical Insulation, vol. 26, no. 5, pp. 1558-1568, 2019.

[9] M. Galea, P. Giangrande, V. Madonna, and G. Buticchi, "ReliabilityOriented Design of Electrical Machines: The Design Process for Machines' Insulation Systems MUST Evolve," IEEE Industrial Electronics Magazine, vol. 14, no. 1, pp. 20-28, 2020.

[10] W. B. Nelson, Accelerated testing: statistical models, test plans, and data analysis. John Wiley \& Sons, 2009.

[11] W. Nelson, "Accelerated Life Testing - Step-Stress Models and Data Analyses," IEEE Transactions on Reliability, vol. R-29, no. 2, pp. 103108, 1980.

[12] M. Marzinotto, C. Mazzetti, and G. Mazzanti, "A New Approach to the Statistical Enlargement Law for Comparing the Breakdown Performance of Power Cables. 1. Theory," IEEE Transactions on Dielectrics and Electrical Insulation, vol. 14, no. 5, pp. 1232-1241, 2007.

[13] G. Mazzanti, "Life and reliability models for high voltage DC extruded cables," IEEE Electrical Insulation Magazine, vol. 33, no. 4, pp. 42-52, 2017.

[14] J. Su, L. Zhao, J. Cheng, P. Yafeng, R. Li, and B. Zeng, "A unified expression for enlargement law on electric breakdown strength of polymers under short pulses: mechanism and review," IEEE Transactions on Dielectrics and Electrical Insulation, vol. 23, no. 4, pp. 2319-2327, 2016.

[15] Q. Zhuang, P. H. F. Morshuis, X. Chen, J. J. Smit, and Z. Xu, "Life prediction of a full-scale transformer winding insulation through statistical analysis of AC voltage endurance test data," IEEE Transactions on Dielectrics and Electrical Insulation, vol. 19, no. 2, pp. 460-471, 2012.

[16] G. C. Stone, I. Culbert, E. A. Boulter, and H. Dhirani, Electrical Insulation for Rotating Machines: Design, Evaluation, Aging, Testing, and Repair. Wiley, 2014.

[17] P. Mancinelli, S. Stagnitta, and A. Cavallini, "Qualification of Hairpin Motors Insulation for Automotive Applications," IEEE Transactions on Industry Applications, vol. 53, no. 3, pp. 3110-3118, 2017.

[18] K. N. Gyftakis, M. Sumislawska, D. F. Kavanagh, D. A. Howey, and M. D. McCulloch, "Dielectric Characteristics of Electric Vehicle Traction Motor Winding Insulation Under Thermal Aging," IEEE Transactions on Industry Applications, vol. 52, no. 2, pp. 1398-1404, 2016.
[19] L. A. Dissado, G. Mazzanti, and G. C. Montanari, "The role of trapped space charges in the electrical aging of insulating materials," IEEE Transactions on Dielectrics and Electrical Insulation, vol. 4, no. 5, pp. 496-506, 1997.

[20] M. S. Naidu and M. K. NAIDU, High voltage engineering. Tata McGraw-Hill Education, 2013.

[21] V. M. Montsinger, "Loading Transformers By Temperature," Transactions of the American Institute of Electrical Engineers, vol. 49, no. 2, pp. 776-790, 1930.

[22] T. W. Dakin, "Electrical Insulation Deterioration Treated as a Chemical Rate Phenomenon," Transactions of the American Institute of Electrical Engineers, vol. 67, no. 1, pp. 113-122, 1948.

[23] "IEEE Standard Test Procedure for Thermal Evaluation of Systems of Insulating Materials for Random-Wound AC Electric Machinery," IEEE Std 117-2015 (Revision of IEEE Std 117-1974), pp. 1-34, 2016.

[24] ASTM International - D1676-17 Standard Test Methods for FilmInsulated Magnet Wire, 2017.

[25] P. Giangrande, V. Madonna, S. Nuzzo, and M. Galea, "Moving Toward a Reliability-Oriented Design Approach of Low-Voltage Electrical Machines by Including Insulation Thermal Aging Considerations," IEEE Transactions on Transportation Electrification, vol. 6, no. 1, pp. 16-27, 2020.

[26] M. Farahani, E. Gockenbach, H. Borsi, K. Schafer, and M. Kaufhold, "Behavior of machine insulation systems subjected to accelerated thermal aging test," IEEE Transactions on Dielectrics and Electrical Insulation, vol. 17, no. 5, pp. 1364-1372, 2010.

[27] V. Madonna, P. Giangrande, L. Lusuardi, A. Cavallini, C. Gerada, and M. Galea, "Thermal Overload and Insulation Aging of Short Duty Cycle, Aerospace Motors," IEEE Transactions on Industrial Electronics, vol. 67, no. 4, pp. 2618-2629, 2020.

[28] E. Kuffel, W. S. Zaengl, and J. Kuffel, High Voltage Engineering: Fundamentals. Newnes, 2000.

[29] G. G. Raju, Dielectrics in electric fields. CRC press, 2016.

[30] V. Madonna, P. Giangrande, G. Migliazza, G. Buticchi, and M. Galea, "A Time-Saving Approach for the Thermal Lifetime Evaluation of Low Voltage Electrical Machines," IEEE Transactions on Industrial Electronics, pp. 1-1, 2019.

[31] V. Madonna, P. Giangrande, and M. Galea, "Evaluation of strand-tostrand capacitance and dissipation factor in thermally aged enamelled coils for low-voltage electrical machines," IET Science, Measurement \& Technology, vol. 13, no. 8, pp. 1170-1177, 2019.

[32] IEC 60034-18-41:2014 Rotating electrical machines - Part 18-41: Partial discharge free electrical insulation systems (Type I) used in rotating electrical machines fed from voltage converters - Qualification and quality control tests 2014.

[33] IEC 60172:2015 Test procedure for the determination of the temperature index of enamelled and tape wrapped winding wires, 2015.

[34] G. Turabee et al., "The Role of Neural Networks in Predicting the Thermal Life of Electrical Machines," IEEE Access, vol. 8, pp. 4028340297, 2020. 